distinguish the intellectual contribution made by Lord Rothschild himself. Karl Jordan said of him in his obituary (Nature 140,574 ; 1937) that

he would have gained high distinction in science without a family name already world-famous. His interest was so intense and so wide, his everready support of science so valuable and his scientific publications so important, that he held a high place of honour in zoology and was elected an honorary fellow by many foreign societies. Entomologists, ornithologist, herpetologists and mammalogist all claimed him as one of their own.

Jordan's obituary is far from flattering or conventional; Miriam Rothschild similarly pulls no punches in dealing with Walter or anyone else in the family; but both agree that Walter Rothschild did make a considerable contribution to science. The present book, from its width of scope and aim at a general readership, was not the one in which to analyse the scientific contributions of Tring in detail. (Yet within these limits a very lucid and adequate indication is given.) It would need a considerable expert to go on to such an analysis, but there is one, Miriam Rothschild.

A.J. Cain is Derby Professor of Zoology at the University of Liverpool.

\section{Briny tales}

\section{Peter J. Smith}

The Mediterranean was a Desert: A

Voyage of the Glomar Challenger.

By Kenneth J. Hsü.

Princeton University Press: 1983. Pp.197. f15.60, \$17.95.

IN 1961, William Ryan and Brackett Hersey discovered a strong seismic reflector 100-200 metres below the Mediterranean sea floor. There was nothing very remarkable about that, you might think; acoustic reflecting horizons are hardly uncommon in either oceanic or continental crust. But even in those early days of reflection profiling this one looked odd, for it ran parallel to the sea bed, mimicking the highly varied topography above. Moreover, in subsequent years the M-reflector, as it came to be called, was traced throughout much of the Mediterranean. It evidently marked the top of some very extensive subsurface deposit.

Ryan's curiosity on this point was finally satisfied in 1970 when, with Kenneth Hsü, he became co-chief scientist on Glomar Challenger's first drilling expedition to the Mediterranean (Leg 13). The M-layer turned out to comprise evaporites (the evaporative residues of sea water), on the surface of which were oozy, basaltic and evaporitic gravels. Though now buried beneath 100 metres or more of marine sediment, which in turn lay beneath 2,000 metres of water, the gravels could only have been the products of subaerial erosion. Furthermore, the evaporites themselves contained components (e.g. anhydrite) formed only in arid, shallowwater zones, even though they were underlain by more deep-water sediments.

Ryan's first reaction to the identification of evaporites was to suppose that they were deposited from deep brine pools similar to those in the Red Sea; but the problem with that is that brine pools precipitate calcium sulphate only in hydrated form (gypsum as opposed to anhydrite). Hsü's alternative hypothesis, which originally appeared the more preposterous, was that prior to the five million years of deposition represented by the seabed sediments, the Mediterranean had dried out completely, turning the area into a huge "death valley". This view, backed by several independent lines of evidence, has largely prevailed. For a million years or more the Mediterranean's link with the Atlantic off Gibraltar was evidently broken, allowing the water to evaporate and deposit its dissolved load.

The development of this remarkable scientific story weaves its way through Hsü's text, which would be interesting enough if that were all it contained. But there is much more to it than that, for Hsü also presents a narrative of the complete two-month voyage in 1970 , making the book as much a human and social document as it is a tale of scientific discovery. Life in a closed, isolated community has its perils at the best of times; but add millions of dollars worth of equipment any piece of which can malfunction at any time, four distinct groups of people (sailors, drillers, marine technicians and scientists) with different outlooks and aspirations, the clash of scientific egos, the vagaries of the weather, the possibility of illness and the perpetual need to make rapid decisions involving huge amounts of money, and you have a mighty explosion looking for somewhere to happen.

That any project could possibly succeed under such circumstances says much for scientists' determination to overcome both nature's notorious reluctance to reveal its secrets and the inclination of human institutions and artefacts to abet nature in its nefarious purpose. That this book succeeds in imparting the flavour of what it must be like to take part in such a knife-edge enterprise likewise says much about Hsü's skill as a communicator, not only of facts and events but also of hopes, fears, elation, despair and, above all, enthusiasm. Hsü has managed to reach parts of the scientific undertaking that most others have been unable or unwilling to reach; and the result is an impressive, if informal and racy, account, for layperson and scientist alike, of the nerve-racking business of wresting information from the Earth's deeper oceanic crust.

Peter J. Smith is Reader in Earth Sciences at the Open University, and editor of Open Earth.

\section{Out of this world}

\section{Jon Darius}

The Atlas of the Solar System.

By Patrick Moore, Garry Hunt, Iain

Nicolson and Peter Cattermole.

Mitchell Beazley/Rand McNally: 1983. Pp.464. £19.95, $\$ 40$.

Publication of an atlas of the Solar System in 1983 is a shrewd choice. The rich veins of planetary imagery mined by Pioneer, Viking and Voyager probes will not be substantially expanded until Voyager 2 reaches Uranus in 1986 . On the other hand, sufficient time has elapsed since the last planetary spectacle to consolidate the observations and map the new territories.

Mitchell Beazley have published a series of four astronomical atlases - The Moon and Jupiter in 1981, The Sun and Saturn in 1982 - each pitched at a lay audience and enjoying the cachet of approval by the Royal Astronomical Society. The Atlas of the Solar System is a compound of these four publications, somewhat condensed and reorganized, and interlarded with new material on the remaining bodies. The publishers have earned a high reputation for "packaging" their books, and happily the Atlas proves the rule: the layout and artwork are exemplary.

Skilful editing generally prevents the seams from showing in the reprinted material, but some quirks occur. Why omit half the photomosaics of the Jovian satellites and half the double spreads on individual lunar regions? Wholesale deletion (or retention) would have been preferable. Let early ring theories, unusual lunar features and the radioheliograph be dropped if need be; but omission of terrestrial aurora looks decidedly odd when both Jovian and Saturnian aurora are included.

The single most serious fault in The Atlas lies in its haphazard distribution of material: $30 \%$ on Jupiter and Saturn, yet $8 \%$ on Mars and a scandalous $3 \%$ on the Earth. Asteroids, comets, meteorites and meteors are vouchsafed a scant few pages; zodiacal dust, not a single word. Despite lip service in the preface, the historical dimension gets short shrift. To call the potted biographies of astronomers erratic is too generous.

But the roses indisputably outnumber the brickbats. I know of no single book, popular or professional, with a better compilation of planetary maps (barring the Earth) - legible, up to date and endowed with complete lists of features. The text is clear and informative. If it is not quite the synthesis to which it aspired, The Atlas is nevertheless handsome, timely and eminently readable.

Jon Darius is Curator of Astronomy at the Science Museum, London. 